\title{
Effect of Pyridoxine on the Metabolism of Tryptophan and Branched-chain Amino Acids in Two Mentally Retarded Sibs
}

\author{
A. F. HEELEY ${ }^{\star}$, DIANA G. McCUBBING, and JEAN SHEPHERD \\ From the Department of Chemical Pathology, The Hospital for Sick Children, Great Ormond Street, \\ and the Institute of Child Health, Guilford Street, London W.C.1
}

There is increasing interest in the importance of pyridoxine in brain disorders of childhood. Convulsions have occurred in infants receiving a pyridoxine (vitamin B6) deficient diet (Coursin, 1955), and Bessey, Adam, and Hansen (1957) have shown that some infants have a greater requirement than others for this vitamin. In the deficiency state, small amounts of vitamin B6 stop the convulsions, but greater than normal amounts are required to correct the increased xanthurenic acid excretion (Bessey et al., 1957). In the dependency states (Scriver, 1960) described in sibs (Waldinger and Berg, 1963), increased excretion of xanthurenic acid has not been a feature, though high doses of vitamin B6 are required to control convulsions.

In 1963, O'Brien and Jensen considered whether vitamin B6 dependency could be a causal factor in mentally retarded persons who did not have convulsions, and during the screening of a mental institution they found two women (aged 17 and 31 years) with evidence of vitamin B6 dependency. These authors suggested that the ratio of the concentrations of 3-hydroxykynurenine and 3-hydroxyanthranilic acid found in urine would be superior to the measurement of the excretion of xanthurenic acid as an indicator of vitamin B6 dependency. The value of this index has been described by Heeley (1965), whose values for the index in normal children agree with those of Michael, Drummond, Doeden, Anderson, and Good (1964).

Biochemical screening of mentally retarded children at The Hospital for Sick Children revealed two sibs who metabolized a tryptophan load abnormally at the pyridoxine-dependent kynureninase reaction. In addition, both sibs had raised levels of leucine in their sera.

Received May 11, 1966.

^ Present address: The Allan Memorial Institute of Psychiatry, 1025 Pine Avenue West, Montreal 2, Quebec, Canada.
Recent work by Belavady, Srikantia, and Gopalan (1963) has shown that high serum levels of leucine in man inhibit the katabolism of tryptophan via kynurenine at some point subsequent to quinolinic acid, resulting in the increased urinary excretion of the latter. Fig. 1 shows the metabolic pathways for the metabolism of tryptophan to nicotinic acid via quinolinic acid.

The purpose of the present investigation was to measure the excretion of quinolinic acid in the sibs, and thus to determine whether a second defect occurred along the metabolic pathway that synthesizes the nicotinamide co-enzymes from tryptophan.

The biochemical aspects of this investigation have been briefly reported elsewhere (Heeley and McCubbing, 1965).

\section{Case Reports}

Case 1. L.H. weighed 3089 g. (6 lb. 13 oz.) at birth, and was delivered at full term by caesarean section for foetal distress, but no resuscitation was required.

Her early development was uneventful. She sat at 6 months, walked alone at 2 years, and said a few single words between 6 and 12 months. Thereafter she did not speak again until 4 years old, and then only single words. At 2 years she seemed to be short-sighted and she has worn glasses since the age of 3 . She has never had any convulsions.

The parents first sought help because of her failure to talk. After the diagnosis of severe mental retardation (IQ 40) had been made, the child was admitted to The Hospital for Sick Children for further investigation at the age of 4 years 11 months.

In the ward she spent her time wandering around aimlessly and peering short-sightedly at people and things. She made frequent loud squealing noises but spoke no proper words, and never played with toys.

On examination she was just on the third centile for height and weight, but apart from severe myopia, nothing of note was found.

Case 2. S.H. the only other child in the family 
Tryptophan $\longrightarrow$ Kynurenine $\rightarrow$ 3-Hydroxykynurenine

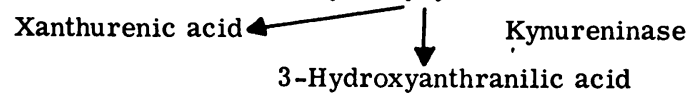

(spontaneous) 2-acroleyl-3-amino

Quinolinic acid

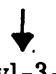

$\stackrel{\downarrow}{\text { Quinolinic acid }}$

ribonucleotide

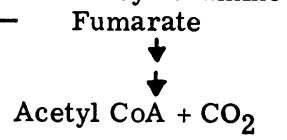

$\downarrow$

Nicotinic acid ribonucleotide<smiles></smiles>

Nicotinamide Adenine Dinucleotide $\rightarrow \mathrm{N}$-methyl-6-pyridone nicotinamide

FIG. 1.-Metabolic pathways for the metabolism of tryptophan to nicotinic acid via quinolinic acid.

weighed $3288 \mathrm{~g}$. (7 lb. $4 \mathrm{oz}$.) at birth, after a normal fullterm pregnancy and delivery. He sat at 8 months, walked at 17 months, and could say Mama and Dada at 6 months. Speech was lost at 1 year of age, but at 3 years he began to say a few single words again.

He was first admitted under the care of Professor Sir Alan Moncrieff at the age of 2 years and 8 months. His appearance was similar to that of his sister. He was very miserable, and wandered around the ward in an aimless fashion. His IQ was 35 . He was just below the 10th centile for height, just above the 70th for weight, and severely myopic. No other physical abnormality was found.

Treatment and progress. Since biochemical investigations (see below) showed an abnormal tryptophan metabolism involving pyridoxine, both children were placed on oral pyridoxine $(10 \mathrm{mg}$. t.d.s.). They showed marked improvement for the first 6 months. When readmitted two months after beginning treatment, they were much happier and less frustrated, and the squealing noises had almost stopped. They took a greater interest in their surroundings and would concentrate on one thing for a longer time. This progress continued, and five months later, when readmitted again, they were saying a number of single words and obeying simple commands.

During the next year, further improvement was much slower, and though both children were more cheerful and responsive compared with previously, the formal IQ of 35 to 40 before treatment did not change.

The abnormal EEG seen before treatment also showed marked improvement during the first 2 months of treatment, but thereafter there was no further change.

\section{Biochemical Investigations}

Tryptophan load tests. Investigations were performed during the initial admission to hospital and at varying intervals after the children were placed on daily supplements of $30 \mathrm{mg}$. pyridoxine.
The metabolites kynurenine ( $\mathrm{K})$, 3-hydroxykynurenine (HK), 3-hydroxyanthranilic acid (HA), quinolinic acid (QA), and xanthurenic acid (XA) were measured in urine collected for a period of 8 hours from the time of administration of an oral load of L-tryptophan $(0 \cdot 1 \mathrm{~g}$. $/ \mathrm{kg}$. body weight). Details of the oral loading procedure, urine collection, and analytical methods for $\mathrm{K}, \mathrm{HK}, \mathrm{HA}$, and XA have been described (Heeley, 1965).

The method used for the separation of QA from other urinary compounds is given in the Appendix.

Serum leucine, valine and iso-leucine. Capillary blood obtained by finger-prick was collected 2 hours after breakfast. The serum was desalted on an ion exchange resin column and the amino acids were separated, identified, and measured by a quantitative paper chromatographic technique (see Appendix).

\section{Results of Biochemical Investigations}

The results of routine biochemical investigations for the two sibs are shown in Table I.

The excretions of the tryptophan metabolites $K$, $\mathrm{HK}, \mathrm{HA}$, and XA and the various ratios for Cases 1 and 2 , while they were receiving (a) normal dietary amounts of pyridoxine (approximately $1 \mathrm{mg}$./day) and (b) supplements of pyridoxine ( $30 \mathrm{mg}$./day) are given in Table II.

The range of metabolite excretions and the mean values for the ratios in 13 control children are given in Table III.

Raised values of $\mathrm{K} / \mathrm{HA}, \mathrm{XA} / \mathrm{HA}$, and $\mathrm{HK} / \mathrm{HA}$, and normal values of $\mathrm{K} / \mathrm{HK}$ were found when the patients were receiving normal dietary amounts of pyridoxine. Normal values for the metabolite excretions and ratios were observed when the patients were retested after receiving the oral pyridoxine supplements for periods varying from 1 week to 1 year 8 months. 
TABLE I

Routine Biochemical Investigations

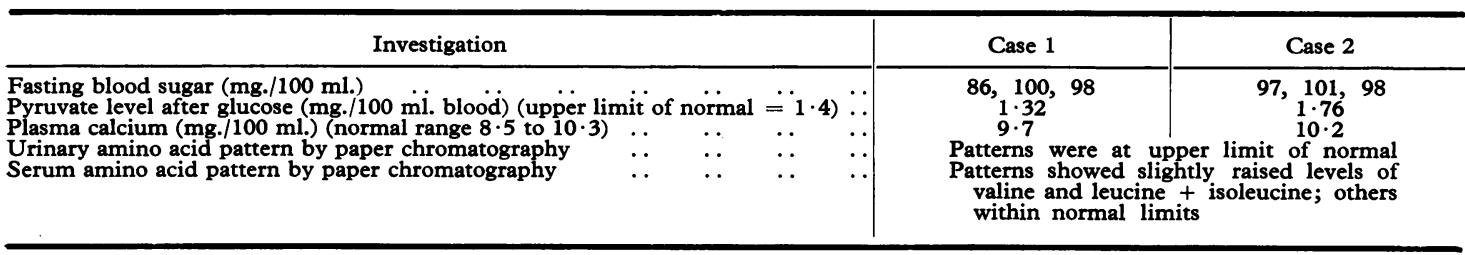

TABLE II

Excretion of Tryptophan Metabolites by Cases 1 and 2 While Receiving Normal Dietary Amount and Supplements of Pyridoxine

\begin{tabular}{|c|c|c|c|c|c|c|c|c|c|}
\hline \multirow{2}{*}{ Patient } & \multirow{2}{*}{$\begin{array}{c}\text { Pyridoxine } \\
\text { Supplement } \\
\text { (30 mg./day) for: }\end{array}$} & $\mathbf{K}$ & HK & HA & $\mathbf{X A}$ & \multirow{2}{*}{$\frac{K}{H K}$} & \multirow{2}{*}{$\frac{K}{H A}$} & \multirow{2}{*}{$\frac{\mathrm{XA}}{\mathrm{HA}}$} & \multirow{2}{*}{$\frac{\text { HK }}{\text { HA }}$} \\
\hline & & \multicolumn{4}{|c|}{$\mu$ mole/kg. body wt. 8 hr. } & & & & \\
\hline Case 1 & $\begin{array}{l}\text { None` } \\
1 \text { wk. } \\
2 \text { mth. } \\
5 \text { mth. } \\
1 \text { yr. } 1 \text { mth. } \\
1 \text { yr. } 8 \text { mth. }\end{array}$ & $\begin{array}{r}11 \cdot 4 \\
8 \cdot 1 \\
2 \cdot 1 \\
3 \cdot 5 \\
4 \cdot 2 \\
3 \cdot 2\end{array}$ & $\begin{array}{r}17 \cdot 5 \\
2 \cdot 8 \\
1 \cdot 3 \\
1 \cdot 9 \\
2 \cdot 7 \\
1 \cdot 3\end{array}$ & $\begin{array}{l}0 \cdot 9 \\
2 \cdot 5 \\
2 \cdot 0 \\
1 \cdot 6 \\
1 \cdot 7 \\
1 \cdot 6\end{array}$ & $\begin{array}{r}11 \cdot 7 \\
1.0 \\
1.0 \\
= \\
=\end{array}$ & $\begin{array}{l}0 \cdot 7 \\
2 \cdot 9 \\
1 \cdot 6 \\
1 \cdot 8 \\
1 \cdot 7 \\
2 \cdot 5\end{array}$ & $\begin{array}{r}12 \cdot 7 \\
3 \cdot 2 \\
1 \cdot 1 \\
2 \cdot 2 \\
2 \cdot 7 \\
2 \cdot 0\end{array}$ & $\begin{array}{r}13.0 \\
0.4 \\
0.5 \\
= \\
=\end{array}$ & $\begin{array}{r}19 \cdot 3 \\
1 \cdot 1 \\
0 \cdot 7 \\
1 \cdot 2 \\
1 \cdot 6 \\
0 \cdot 8\end{array}$ \\
\hline Case 2 & $\begin{array}{l}\text { None* } \\
1 \text { wk. } \\
2 \text { mth. } \\
5 \text { mth. } \\
1 \text { yr. } 1 \mathrm{mth} . \\
1 \text { yr. } 8 \mathrm{mth} .\end{array}$ & $\begin{array}{r}17 \cdot 7 \\
3 \cdot 7 \\
1 \cdot 5 \\
3 \cdot 4 \\
2 \cdot 1 \\
2 \cdot 3\end{array}$ & $\begin{array}{r}17 \cdot 1 \\
0.9 \\
1 \cdot 0 \\
1.5 \\
1 \cdot 7 \\
1 \cdot 8\end{array}$ & $\begin{array}{l}1 \cdot 1 \\
2 \cdot 0 \\
2 \cdot 6 \\
2 \cdot 0 \\
1 \cdot 8 \\
2 \cdot 8\end{array}$ & $\begin{array}{r}12.8 \\
0.9 \\
0.6 \\
-\end{array}$ & $\begin{array}{l}1 \cdot 0 \\
4 \cdot 3 \\
1 \cdot 5 \\
2 \cdot 3 \\
1 \cdot 2 \\
2 \cdot 2\end{array}$ & $\begin{array}{r}16 \cdot 0 \\
1 \cdot 8 \\
0 \cdot 6 \\
1 \cdot 7 \\
1 \cdot 2 \\
1 \cdot 0\end{array}$ & $\begin{array}{r}11.6 \\
0.5 \\
0.3 \\
=\end{array}$ & $\begin{array}{r}15 \cdot 6 \\
0.5 \\
1.4 \\
0.8 \\
0.9 \\
0.5\end{array}$ \\
\hline
\end{tabular}

$\star$ Tested while receiving normal dietary amounts of pyridoxine. $\mathrm{K}=$ kynurenine; $\mathrm{HK}=3$-hydroxykynurenine; $\mathrm{HA}=3$-hydroxyanthranilic acid; and $\mathrm{XA}=$ xanthurenic acid.

TABLE III

Excretion of Tryptophan Metabolites by 13 Control Children Receiving Normal Dietary Amounts of Pyridoxine

\begin{tabular}{|c|c|c|c|c|c|c|c|c|}
\hline \multirow{2}{*}{$\begin{array}{c}\text { Age } \\
\text { (range) }\end{array}$} & \multicolumn{4}{|c|}{$\mu$ mole/kg. body wt. $8 \mathrm{hr}$. (range) } & \multicolumn{4}{|c|}{ Mean \pm SD } \\
\hline & $\mathbf{K}$ & HK & HA & $\mathbf{X A}$ & $\frac{\mathrm{K}}{\mathrm{HK}}$ & $\frac{K}{H A}$ & $\frac{\mathrm{XA}}{\mathrm{HA}}$ & $\frac{\mathrm{HK}}{\mathrm{HA}}$ \\
\hline 2 mth. -9 yr. & $0 \cdot 9-22 \cdot 8$ & $0 \cdot 6-6 \cdot 0$ & $0 \cdot 8-5 \cdot 1$ & $0 \cdot 1-2 \cdot 4$ & $2 \cdot 3 \pm 1 \cdot 0$ & $2 \cdot 2 \pm 1 \cdot 2$ & $0.4 \pm 0.3$ & $1 \cdot 0 \pm 0.4$ \\
\hline
\end{tabular}

* For abbreviations see Table II.

\section{TABLE IV}

Excretion of Quinolinic Acid by Cases 1 and 2 and by Control Subjects: Effect of Pyridoxine

\begin{tabular}{c|c|c}
\hline Case No. & $\begin{array}{c}\text { Pyridoxine Intake } \\
\text { (mg./day) }\end{array}$ & $\begin{array}{c}\text { Quinolinic Acid } \\
\mu \text { mole/kg. body } \\
\text { wt. 8 hr. }\end{array}$ \\
\hline 2 & $1^{\star}$ & $2 \cdot 7$ \\
1 & 1 & 2.9 \\
2 & 30 for 1 wk. \\
2 & 30 for 2 mth. & 1.4 \\
2 & 30 for 5 mth. & 1.2 \\
1 & 30 for 1 wk. & 1.7 \\
1 & 30 for 5 mth. & 1.4 \\
Control & 1 & $1.9 \pm 0.8 \dagger$ \\
\hline
\end{tabular}

* $1 \mathrm{mg}$. is the approximate amount in the normal diet. + Mean $\pm S D$.
QA was measured in the 8-hour urines of (a) both the patients when they were receiving both normal dietary amounts and oral supplements of pyridoxine, (b) 8 control children when they were receiving normal dietary amounts of pyridoxine, (c) 2 mentally defective children with convulsions who metabolized the tryptophan load abnormally (raised HK/HA and XA/HA) but who had normal serum amino acid patterns, and (d) 2 phenylketonuric children who were receiving normal diets and whose serum phenylalanine levels were greater than 15 $\mathrm{mg} . / 100 \mathrm{ml}$.

QA excretions, expressed as $\mu$ moles $/ \mathrm{kg}$. body weight per $8 \mathrm{hr}$., for the sibs, L.H. and S.H., and the control subjects (mean \pm SD) are given in Table IV. 
Effect of Pyridoxine on Tryptophan Metabolism in Retardation

TABLE V

Concentrations of Branched-chain Amino Acids in Serum: Effect of Pyridoxine

\begin{tabular}{|c|c|c|c|c|}
\hline Case No. & $\begin{array}{l}\text { Pyridoxine Intake } \\
\text { (mg./day) }\end{array}$ & Leucine & $\begin{array}{c}\text { Valine } \\
\text { (mg./100 ml. serum) }\end{array}$ & Isoleucine \\
\hline $\begin{array}{c}2 \\
2 \\
1 \\
1 \\
12 \text { control children } \\
\text { (age range } 2 \text { yr.-11 yr.) } \\
2 \\
1\end{array}$ & $\begin{array}{l}1 * \\
1 \\
1 \\
1 \\
1 \\
30 \\
30\end{array}$ & $\begin{array}{c}4 \cdot 0 \\
3 \cdot 9 \\
3 \cdot 4 \\
3 \cdot 5 \\
1 \cdot 6 \pm 0 \cdot 7 \ddagger \\
1 \cdot 8 \pm 0 \cdot 6 \ddagger \\
1 \cdot 3 \pm 0 \cdot 3 \ddagger\end{array}$ & $\begin{array}{c}4 \cdot 5 \\
4 \cdot 4 \\
1 \cdot 4 \\
2 \cdot 5 \\
2 \cdot 7 \pm 0 \cdot 6 \\
2 \cdot 2 \pm 0 \cdot 7 \\
2 \cdot 2 \pm 0 \cdot 2\end{array}$ & $\begin{array}{c}1.7 \\
1.8 \\
0.7 \\
0.9 \\
0.9 \pm 0.4 \\
0.9 \pm 0.3 \\
0.8 \pm 0.2\end{array}$ \\
\hline
\end{tabular}

* $1 \mathrm{mg}$. is the approximate amount of pyridoxine in a normal diet.

+ Mean \pm SD.

$\ddagger$ Mean $\pm S D$ of 13 estimations while receiving pyridoxine supplements for periods varying from 1 week to 1 year 8 months.

The QA excretions in both the sibs were greater when they were receiving normal amounts of pyridoxine than when they were receiving the pyridoxine supplements. The data were insufficient to demonstrate a significant difference between the QA excretions in the sibs and the control group when receiving normal dietary amounts of pyridoxine.

When the values for $\mathrm{HK} / \mathrm{HA}$ were raised, the excretions of HA were decreased. It was likely, therefore, that the defect at the kynureninase step would reduce the amount of $\mathrm{HA}$ for further metabolism via QA. It seemed relevant, therefore, to express QA excretion as a ratio to the excretion of $\mathrm{HA}$, the precursor in the metabolic pathway.

Fig. 2 shows that (a) this ratio, QA/HA, was relatively constant for the control group, (b) the ratio for Cases 1 and 2 was grossly raised when they

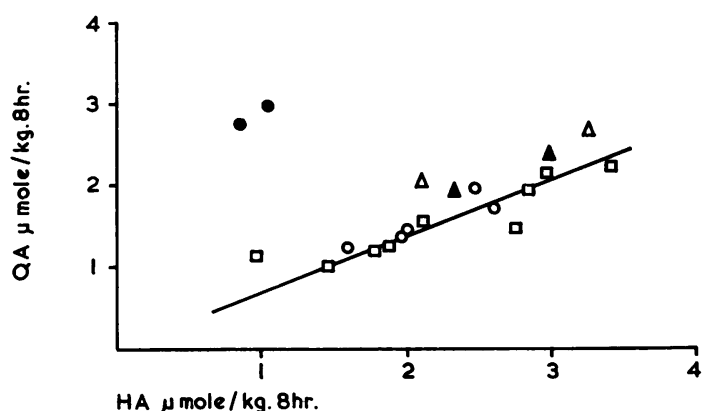

FIG. 2.-The relationship of the excretion of quinolinic acid to 3-hydroxyanthranilic acid in various children.

- Cases 1 and 2 receiving 1 mg. pyridoxine/day.

- Cases 1 and 2 receiving $30 \mathrm{mg}$. pyridoxine/day.

$\square$ Control subjects receiving 1 mg. pyridoxine/day.

$\triangle$ Children with convulsions and raised values of HK/HA receiving $1 \mathrm{mg}$. pyridoxine/day.

$\Delta$ Untreated phenylketonuric children receiving $1 \mathrm{mg}$. pyridoxine/day.

The slope of the line gives the mean value for $Q A / H A$ in the control children. were receiving normal amounts of pyridoxine but was normal when they were receiving $30 \mathrm{mg}$./day, (c) the values of QA/HA for the two children with convulsions and raised $\mathrm{HK} / \mathrm{HA}$ were not significantly different from the values of QA/HA for the control children, and (d) there was no significant difference between the QA/HA values for control children and two untreated phenylketonuric children.

The values for the branched-chain amino acids (mg./100 ml. serum) in the two sibs and normal children are shown in Table $V$. When receiving normal dietary amounts of pyridoxine Cases 1 and 2 had slightly raised values for leucine and Case 2 also had raised values for valine. Isoleucine levels were within the normal range for both patients.

When the children were given pyridoxine supplements the serum levels of leucine and valine were found to be consistently within the normal range of values. The mean values $( \pm S D)$ for 13 estimations of the serum amino acids when the patients were receiving extra pyridoxine are shown in Table $\mathrm{V}$.

\section{Discussion}

The increased excretions of $\mathrm{K}, \mathrm{HK}$, and $\mathrm{XA}$ in conjunction with a low HA excretion when Cases 1 and 2 were receiving approximately $1 \mathrm{mg}$. pyridoxine per day, i.e. normal diet, and the normal excretion patterns of these metabolites when they were receiving $30 \mathrm{mg}$. pyridoxine per day suggested that the normal dietary intake of the vitamin was insufficient for normal kynureninase activity.

The normal serum levels of leucine and valine when the two sibs were receiving pyridoxine supplements suggested that some relation existed between the increased requirement of the kynureninase reaction for pyridoxine and the raised serum levels of leucine, and also of valine in Case 2, originally observed in these patients. The nature of such a relation is not known.

When the serum concentrations of leucine were 
raised in both the patients, significantly raised values of urinary QA/HA were found also, and both abnormalities reverted to normal when they were receiving pyridoxine supplements. Two children with convulsions and raised values of $\mathrm{HK} / \mathrm{HA}$ were found to have normal values for $\mathrm{QA} / \mathrm{HA}$ and it seemed unlikely, therefore, that increased concentrations of either $\mathrm{K}, \mathrm{HK}$, or XA inhibited the further metabolism of tryptophan at some stage subsequent to QA. Two phenylketonuric children were found to have normal values for QA/HA.

Gopalan and Srikantia (1960) described the increased incidence of pellagra in Indian populations whose staple cereal diet contained a relatively high leucine content. Belavady et al. (1963) investigated the effect of the oral administration of leucine on tryptophan metabolism in humans. High serum levels of leucine resulted in an increased urinary excretion of QA. The finding of a decreased excretion of $\mathrm{N}$-methyl-6-pyridone nicotinamide suggested that leucine inhibited an enzyme in the pathway, but neither the site nor the mechanism of the inhibition were determined. The serum leucine levels of the subjects investigated by Belavady et al. (1963) were not reported, but the size of oral leucine loads administered makes it likely that they were considerably greater than the levels in the two children reported here. The finding that increased QA excretion accompanied raised serum leucine levels in these children seemed to confirm the observations of Belavady et al. (1963).

The identical biochemical and clinical findings in both sibs are suggestive of an inborn error of metabolism. Preliminary investigations have revealed that the mother of the children, but not the father, metabolizes a tryptophan load abnormally with raised values for HK/HA. In early life it is probable that the endogenous synthesis of nicotinic acid is the major source of nicotinamide co-enzymes, a diminished supply of which might be expected to have a damaging effect on the developing nervous system. In the two mentally retarded sibs studied, it was demonstrated that under the 'stress' of a tryptophan load, defects existed at two separate sites along the tryptophan-nicotinamide pathway. It is possible that such an impairment would lead to a decreased availability of co-enzymes required for energy-producing reactions during brain development.

\section{Summary}

Two mentally retarded sibs, a girl aged 5 years and a boy aged 3 years, are described. Both children were found to have slightly raised serum concentrations of leucine and the boy also had a raised serum concentration of valine. In both children, tryptophan loading studies revealed a disorder of metabolism which involved the pyridoxaldependent enzyme, kynureninase. The administration of oral pyridoxine supplements corrected the abnormality of tryptophan metabolism and reduced the raised serum levels of leucine found in both sibs, and of valine in the boy, to normal. The relation between the defects of tryptophan and branchedchain amino acid metabolism was demonstrated when quinolinic acid was measured in the urine both before and after the administration of pyridoxine. The possible relation between the biochemical and clinical findings is discussed.

We thank Dr. Barbara E. Clayton for her advice and continual encouragement throughout this investigation. We are grateful to Professor Sir Alan Moncrieff for permission to investigate patients under his care; Dr. A. D. Patrick and Dr. G. E. Roberts for helpful discussions; and Sister E. M. Baldwin and the Nursing Staff for supervising the urine collections. We gratefully acknowledge the financial support of the Nuffield Foundation and the Joint Research Board of The Hospital for Sick Children and the Institute of Child Health.

\section{REFERENCES}

Belavady, B., Srikantia, S. G., and Gopalan, C. (1963). The effect of the oral administration of leucine on the metabolism of tryptophan. Biochem. $\mathcal{F}$., 87, 652.

Bessey, O. A., Adam, D. J. D., and Hansen, A. E. (1957). Intake of vitamin $\mathbf{B}_{6}$ and infantile convulsions : a first approximation of requirements of pyridoxine in infants. Pediatrics, 20, 33.

Clayton, B. E., Moncrieff, A. A., Pampiglione, G., and Shepherd, J. (1966). Biochemical and EEG studies in phenylketonuric children during phenylalanine tolerance. Arch. Dis. Childh., 41, 267.

Coursin, D. B. (1955). Vitamin $\mathbf{B}_{6}$ deficiency in infants. Amer. $\mathcal{F}$. Dis. Child., 90, 344.

Gopalan, C., and Srikantia, S. G. (1960). Leucine and pellagra. Lancet, 1, 954.

Heeley, A. F. (1965). The effect of pyridoxine on tryptophan metabolism in phenylketonuria. Clin. Sci., 29, 465.

-, and McCubbing, D. G. (1965). The effect of pyridoxine on an abnormal metabolism of tryptophan and leucine in two mentally retarded siblings. In Proc. 2nd Meeting, Federation of European Biochemical Societies, p. 65. E. Werner, Vienna.

Henderson, L. M., and Hirsch, H. M. (1949). Quinolinic acid metabolism. $\mathcal{F}$. biol. Chem., 181, 667.

Michael, A. F., Drummond, K. N., Doeden, D., Anderson, J. A., and Good, R. A. (1964). Tryptophan metabolism in man. f. clin. Invest., 43, 1730.

O'Brien, D., and Jensen, C. B. (1963). Pyridoxine dependency in two mentally retarded subjects. Clin. Sci., 24, 179.

Price, J. M. (1954). Determination of N-methyl-2-pyridole-5carboxamide in human urine. $\mathcal{F}$. biol. Chem., 211, 117.

Scriver, C. R. (1960). Vitamin $\mathbf{B}_{6}$ dependency and infantile convulsions. Pediatrics, 26, 62.

Waisman, H. A., and Elvehjem, C. A. (1941). Chemical estimation of nicotinic acid and vitamin $\mathrm{B}_{6}$. Ind. Engng. Chem. analyt. Edn., 13, 221.

Waldinger, C., and Berg, R. B. (1963). Signs of pyridoxine dependency manifest at birth in siblings. Pediatrics, 32, 161 .

Work, E. (1948). The amino acids present in trypsin and the trypsin inhibitor from soya bean. Biochem. f., 42, 49. 


\section{Appendix}

\section{Methods and Materials}

Serum branched-chain amino acids. Serum branched-chain amino acids were separated and measured by the paper chromatographic technique previously described by Clayton, Moncrieff, Pampiglione, and Shepherd (1966). The solvent system employed for the separation of these amino acids has been described by Work (1948).

Tertiary amyl alcohol (200 ml.) was shaken with distilled water $(200 \mathrm{ml}$.) in a separating funnel. The lower aqueous layer was run into the bottom of the chromatography tank and diethylamine $(2 \mathrm{ml}$.) was added. The serum extracts were applied to the paper, dried, and allowed to equilibrate in the tank overnight at room temperature. The papers were then developed (descending solvent technique) in the water-saturated tertiary amyl alcohol for 56 hours.

Measurement of quinolinic acid in urine. Quinolinic acid was separated from other urinary compounds by ion exchange chromatography. The colorimetric estimation was based on decarboxylation (Henderson and Hirsch, 1949) followed by cleavage of the pyridine ring and condensation of the resulting glutaconic aldehyde with a primary aromatic amine (Waisman and Elvehjem, 1941).

Analytical grade reagents were used throughout the procedure. Quinolinic acid (puriss) was obtained from Koch-Light Laboratories Ltd. Standard solutions of $\mathrm{QA}$ in water $\left(40 \mathrm{mg}\right.$. $/ 100 \mathrm{ml}$.) were stable at $5^{\circ} \mathrm{C}$. for at least 4 weeks.

Method. Dowex $50\left(\mathrm{H}^{+}\right)$resin was prepared according to the method of Price (1954). Dowex 1 $\left(\mathrm{Cl}^{-}\right)$was converted to the formate form by running $5 \mathrm{~N}-\mathrm{HCOOH}(20 \mathrm{vol}$.) through the resin $(1 \mathrm{vol}$.) packed in a column. The resin was then washed with water (10 vol.) and stored in $1 \mathrm{~N}-\mathrm{HCOOH}$. Immediately before use the Dowex $1(-\mathrm{COOH})$ resin $(1$ vol.) was washed with $2 \mathrm{~N}-\mathrm{HCOOH}(5$ vol.) then with water ( 8 vol.). Concentrated $\mathrm{HCl}(0 \cdot 15 \mathrm{ml}$.) was added to the urine $(3.0 \mathrm{ml}$.), diluted to $20 \mathrm{ml}$. with water, and passed through a column of Dowex $50\left(\mathrm{H}^{+}\right)$resin $(3 \mathrm{~cm} . \times 1$ $\mathrm{cm}$.). The effluent was collected and the column was then washed with water $(5 \mathrm{ml}$.).

In order to separate the precursors of the urinary pigments from QA, the effluent and washings were combined and passed through a column of Dowex 1 $(-\mathrm{COOH})$ resin $(3 \mathrm{~cm} . \times 1 \mathrm{~cm}$.$) . The column was$ washed with water and the effluent discarded. QA was eluted with $0.1 \mathrm{~N}-\mathrm{HCl}(30 \mathrm{ml}$.). The concentrated eluates did not react with cyanogen bromide/o-tolidine, and therefore did not contain nicotinic acid or nicotinamide.

The Dowex 1 eluate $(30 \mathrm{ml}$.) was evaporated to dryness in a rotary evaporator at $55^{\circ} \mathrm{C}$. and the residue dissolved in glacial acetic acid $(2.0 \mathrm{ml}$.). An aliquot $(1.0$ ml.) was heated at $105^{\circ} \mathrm{C}$. in a sealed glass tube for 3 hours. Under these conditions QA was reproducibly decarboxylated to the extent of $90 \%$. On cooling, the solution was diluted with water, adjusted to $p \mathrm{H}$ 4-5 with $2 \mathrm{~N}-\mathrm{NaOH}$, and made up to $25 \mathrm{ml}$. in a volumetric flask. A sample of this solution $(2.0 \mathrm{ml}$.) was mixed with ethanol ( $3.0 \mathrm{ml}$.) followed by $4 \%$ (w/v) aqueous cyanogen bromide $(1.0 \mathrm{ml}$.) and o-tolidine $(1.0 \mathrm{ml} .1 \%(\mathrm{w} / \mathrm{v})$ in ethanol). Extinctions were measured at $465 \mathrm{~m} \mu$. after 25 minutes in $1 \mathrm{~cm}$. cuvettes using a Hilger and Watts Uvispek spectrophotometer. Extinctions were linear within the experimental range of nicotinic acid (i.e. urinary QA) concentrations, and the reaction product at maximum colour development was stable for several minutes. A solution of glacial acetic acid $-\mathrm{NaOH}(p \mathrm{H}$ 4.5 ) and cyanogen bromide/o-tolidine was used for the blank setting of the instrument.

Standard amounts of QA (40 pig) were added to urine samples $(3.0 \mathrm{ml}$.) and carried through the entire procedure. Under these conditions the mean recovery of QA was $87 \% \pm 12 \%$ (SD). 